\title{
Gastos tributários e o financiamento do Sistema Único de Saúde - SUS: os efeitos sobre a equidade e o modelo de atenção à saúde
}

\author{
Luiz Fernando Gonçalves PORTO(1)
}

Recebido: 28 jan 2019 Aceito: 10 fev 2019

Autor de correspondência: Ifporto@yahoo.com

Conflito de interesses: Os autores declaram não haver nenhum interesse profissional ou pessoal que possa gerar conflito de interesses em relação a este manuscrito.

\footnotetext{
${ }^{(1)}$ Escola de Saúde Pública do Estado de Minas Gerais - EPS-MG, Belo Horizonte, MG, Brasil.
}

\section{Resumo}

O Sistema Único de Saúde - SUS, desde sua criação, tem sido marcado por avanços e retrocessos em seus mecanismos de financiamento que impactam na concretização de seus objetivos constitucionais de garantir o direito à saúde universal, equânime e integral. Neste processo, a renúncia fiscal com gastos relacionados à saúde tem importante peso nas contas públicas. Em 2005, segundo Andreazzi e Ocké-Reis (2007, p. 4) "o valor da renúncia de arrecadação fiscal relativa às despesas com planos de saúde e aos desembolsos diretos com a assistência médico-hospitalar girou em torno de $R \$ 2,8$ bilhões". Já para o orçamento de 2017, a estimativa de perda de arrecadação com despesas médicas do Imposto de Renda da Pessoa Física - IRPF, apresentada pela Receita Federal do Brasil, foi de cerca de $\mathrm{R} \$ 13,1$ bilhões (BRASIL/MF, 2017). Neste cenário Este resumo, fruto do Trabalho de Conclusão de Curso apresentado na Especificação em Direito Sanitário pela Escola de Saúde Pública do Estado de Minas Gerais ESP-MG em 2017, tem como objetivo analisar a relação entre os gastos tributários (renúncia fiscal) e o processo de subfinanciamento do SUS, considerando-se o princípio da equidade e o modelo de atenção à saúde previsto na Constituição Federal de 1988. Para tanto o estudo analisa as estimativas de perda de arrecadação, com base nos "Demonstrativo dos gastos governamentais indiretos de natureza tributária" (Demonstrativo de Gastos Tributários - DGT) elaborados anualmente pela Receita Federal do Brasil e a literatura a respeito do temam promovendo uma abordagem quantitativa e qualitativa. Dentre diversos dispositivos que contribuíram para o (des)financiamento da saúde, existe um mecanismo silencioso que tem grande relevância e que acompanha o processo de subfinanciamento do SUS ao longo de sua história. Trata-se dos gastos tributários, que dizem respeito a renúncia de receitas promovida pelo Governo por meio da concessão de benefícios fiscais. Mendes e Weiller (2015) lembrem que após a EC 29/2000. "[...] a fragilidade do financiamento [do SUS] foi percebida no crescimento da renúncia fiscal decorrente da dedução dos gastos com planos de saúde e símiles no Imposto de Renda e das concessões fiscais às entidades privadas sem fins lucrativos (hospitais) e à indústria químicofarmacêutica, enfraquecendo a capacidade de arrecadação do Estado brasileiro" (MENDES E WEILLER, 2015, p. 492). Ou seja, a utilização deste mecanismo impacta diretamente no volume de recursos a serem aplicados diretamente nas 
ações e serviços de saúde, além de gerar diversas implicações sobre o modelo da política pública de saúde proposto pela CF/88. A primeira vez em que o conceito de gasto tributário foi utilizado data de 1967. Conforme documento da Comissão Econômica para a América Latina (CEPAL) citado por Andreazzi e Ocké-Reis (2007, p. 523): "[...] referindo-se aos dispositivos existentes na legislação do imposto de renda, isenções e outros benefícios fiscais [...] esses benefícios constituíam-se em gastos do governo realizados por intermédio da redução da carga tributária, ao invés de um desembolso direto (CEPAL/PNUD, 1991, p. 43). Nos gastos em saúde estão compreendidas imunidades e isenções tributárias, redução de alíquotas e deduções sobre bases de cálculo para os seguintes itens: (a) Água Mineral; (b) Assistência Médica, Odontológica e Farmacêutica a Empregados (deduzidas do IRPJ); (c) Despesas Médicas (deduzidas do IRPF); (d) Entidades Filantrópicas; (e) Entidades sem Fins Lucrativos - Assistência Social e Saúde; (f) Equipamentos para uso médico, hospitalar, clínico ou laboratorial; (g) Medicamentos; (h) Produtos Químicos e Farmacêuticos; (i) Programa Nacional de Apoio à Atenção da Saúde da Pessoa com Deficiência (Pronas/PCD); e (j) Programa Nacional de Apoio à Atenção Oncológica - Pronon. O montante do gasto tributário em saúde (GTS), conforme dados dos DGT analisados (20122018), apresenta uma trajetória de queda, em termos percentuais relativos ao gasto tributário total, entre 2012 e 2015 (de 13,6\% para 8,9\%), e posterior retomada de elevação entre 2016 e 2018 (de 11,6\% para 13,7\%) Todavia, em termos absolutos, apenas o ano de 2015 apresentou ligeira queda - cerca de $R \$$ 200 milhões a menos que o ano anterior. Segundo os referidos Demonstrativos, os GTS passaram de R $\$ 28,3$ bilhões, em 2012, para R $\$ 39$ bilhões, em 2018. As despesas médicas apresentam os maiores volumes de GTS, correspondendo a cerca de $40 \%$ do total no período. Em seguida aparecem os medicamentos (16\%) e a assistência à saúde de empregados (15\%). A renúncia fiscal com entidades, filantrópicas e sem fins lucrativos, correspondem a 19\%. Esses cinco itens respondem por cerca de 95\% dos gastos estimados entre os anos de 2012 e 2018. O volume de deduções concentrado nestes itens aponta para uma transferência de recursos para o setor privado, gerando iniquidades na tributação e fortalecendo o setor privado de planos de saúde, Neste aspecto Sayd (2003) afirma: "[...] o valor da renúncia fiscal é determinado pelo valor da alíquota utilizada, que é definida de acordo com o rendimento tributável líquido. Isto significa que as deduções favorecem principalmente os contribuintes que se encontram nas faixas de rendimentos superiores" (SAYD, 2003, p. 47). A autora aponta que: "[...] a renúncia fiscal motivada pelas deduções com despesas em saúde estaria conceitualmente mais de acordo com os objetivos dos incentivos que das isenções tributárias. Cabe lembrar que os incentivos visam induzir comportamento estimulando os agentes a agir de determinada forma objetivando atingir um alvo econômico ou social previamente definido, enquanto que a isenção visa beneficiar a quem não tenha capacidade econômica para suportar o ônus do tributo e tentar garantir um padrão mínimo de bem estar social à população mais carente" (SAYD, 2003, p. 81). Nesse cenário é necessário 
aprofundar estudos sobre o real impacto financeiro dos gastos tributários no SUS, mas, também, é preciso estar atento às forças que atuam pressionando os centros de poder. A ação de grupos de interesse nesse campo tem se mostrado forte, haja vista as últimas investidas sobre o SUS no que diz respeito à ampliação da participação privada ou do congelamento dos gastos públicos. Diante disso renúncia fiscal, a depender de sua finalidade, pode ser vista como parte de um processo maior de desmonte do SUS, em particular, e do arcabouço jurídicoinstitucional das políticas sociais no Brasil.

Descritores: Financiamento da Assistência à Saúde; Equidade. Política de saúde. 